\title{
PEMANFAATAN KBBI V DARING DALAM PENGAJARAN BAHASA INDONESIA DI SEKOLAH DASAR
}

\section{UTILIZATION OF KBBI V ONLINE IN INDONESIAN LANGUAGE TEACHING IN ELEMENTARY SCHOOL}

\author{
Sutrisno \\ SD Negeri 013 Babulu \\ Jl.Simpang Gunung Intan Babulu Darat, Babulu \\ Penajam Paser Utara Kode pos 76385 \\ Pos-el: sutrisnok809@gmail.com
}

*) Naskah diterima: 8 Oktober 2019; direvisi: 2 Desember 2019; disetujui: 3 Desember 2019

\begin{abstract}
Abstrak
Tulisan ini bertujuan untuk mendeskripsikan pemanfaatan KBBI V versi daring dalam pengajaran bahasa Indonesia di sekolah dasar. Pembelajaran bahasa di sekolah dasar sering menjadi kendala karena banyak kata tidak baku yang digunakan siswa. Hal ini terjadi karena dari kebiasaan awal ataupun memang sama sekali belum mengetahui penulisan yang benar. Kita memahami bahwa berbahasa Indonesia dengan baik dan benar merupakan salah satu bentuk untuk mempertahankan bahasa Indonesia. Oleh karena itu, perlu pembinaan penggunaan bahasa yang baik dan benar kepada siswa sekolah dasar melalui pemanfaatan KBBI V versi daring dalam pengajaran bahasa Indonesia. Perlu dipahami bersama bahwa bahasa itu dinamis dan terus berkembang sesuai dengan kemajuan zaman. Dengan demikian, kesejalanan dan kesejajaran pengajaran bahasa Indonesia di sekolah dasar dengan kebiasaan membuka atau memanfaatkan KBBI V versi daring ini merupakan hal yang harus dijalankan. Hal tersebut juga dimaksudkan untuk membiasakan siswa sekolah dasar dalam penggunaan bahasa Indonesia ini dapat dipraktikkan dengan benar, baik dalam penggunaan bahasa lisan maupun tulisan. Selanjutnya, pembelajaran bahasa Indonesia dengan kebiasaan membuka KBBI V daring akan lebih memaksimalkan pemahaman dan penggunaan katakata baku sehingga kesalahan-kesalahan dapat diminimalisasikan.
\end{abstract}

Kata kunci: pemanfaatan, KBBI V daring, pembelajaran, bahasa dan sastra, sekolah dasar Abstract

\begin{abstract}
This paper aims to describe the utilization of the online version of KBBI $V$ in teaching Indonesian in elementary schools. Language learning in elementary schools is often an obstacle because many nonstandard words are used by students. This happens because of the initial habits or indeed did not know the correct writing. We understand that speaking Indonesian properly and correctly is one form of maintaining Indonesian. Therefore, it is necessary to foster good and correct use of language to elementary school students through the use of online versions of KBBI V in teaching Indonesian. It needs to be understood together that language is dynamic and continues to develop in accordance with the progress of the times. Thus, the alignment and alignment of Indonesian language teaching in primary schools with the habit of opening or utilizing the online version of KBBI $V$ is something that must be carried out. It is also intended to familiarize elementary school students with the use of Indonesian can be practiced correctly, both in the use of spoken and written languages. Furthermore, learning Indonesian
\end{abstract}


with the habit of opening KBBI V online will further maximize the understanding and use of standard words so mistakes can be minimized.

Keywords: utilization, KBBI V online, learning, language and literature, elementary school

\section{PENDAHULUAN}

Pembelajaran bahasa di sekolah dasar sangatlah penting dan memiliki alasan kuat untuk dilakukan. Hal ini dikarenakan bahasa merupakan sarana pendukung ilmu dan teknologi yang terus berkembang. Salah satu tujuan mata pelajaran bahasa Indonesia di sekolah adalah agar peserta didik memiliki kemampuan berkomunikasi secara efektif dan efisien. Pada sisi lain juga harus sesuai dengan etika yang berlaku, baik secara lisan maupun tulis. Kitajuga harus mampu menghargai dan bangga menggunakan bahasa Indonesia sebagai bahasa persatuan dan bahasa negara. Di samping itu, kita seyogyanya memahami bahasa Indonesia, dan dapat menggunakannya dengan tepat, dan kreatif untuk meningkatkan kemampuan intelektual. Berdasarkan tujuan tersebut, pembelajaran bahasa Indonesia diarahkan agar siswa memiliki kemampuan berbahasa yang memadai agar siswa mampu menyampaikan gagasan, perasaaan, dan pengalaman kepada orang lain secara komunikatif.

Namun, dalam kenyataannya masih banyak kekeliruan atau kesalahan yang dilakukan siswa sekolah dasar dalam berkomunikasi di sekolah, khususnya dalam situasi formal. Kesalahan ini sering dilakukan siswa sekolah dasar karena sebagian besar dari mereka banyak yang kurang memahami kata yang digunakannya. Kesalahan atau kekeliruan yang dimaksud, salah satunya dalam menuliskan kalimat masih banyak menggunakan kata yang tidak baku. Hal ini perlu bimbingan dan penjelasan dari guru. Sejak sekolah dasar, diharapkan siswa sudah diperkenalkan dengan kata-kata yang baku dalam bahasa Indonesia. Hal ini sangat penting karena dalam situasi formal, bahasa yang digunakan adalah bahasa ragam baku, baik dalam ranah tulisan maupun lisan. Kita semua berkewajiban menanamkan sikap positif berbahasa Indonesia sejak dini. Penanaman sikap itu dengan tetap mempertahankan bahasa Indonesia. Siswa sekolah dasar juga harus ditanamkan rasa cinta dan bangga berbahasa Indonesia.

Wujud dari rasa bangga berbahasa Indonesia tersebut, di antaranya, dengan terus belajar bahasa Indonesia. Kita juga harus bangga menggunakan bahasa Indonesia sesuai dengan konteksnya agar bahasa kita dapat berkembang dan sejajar dengan bahasa-bahasa asing di dunia.

Betapa repot seandainya Negara Kesatuan Republik Indonesia dengan ribuan pulau dan ratusan bahasa daerah apabila tanpa ada bahasa persatuan. Dengan adanya bahasa persatuan, kita di manapun di belahan bumi Indonesia tidak akan kebingungan untuk berinteraksi antarsuku yang ada di Indonesia.

Dari beberapa alasan serta latar belakang tersebut, perlu adanya pemahaman, pendalaman, serta pembinaan kepada siswa sejak di sekolah dasar untuk menggunakan bahasa Indonesia dengan baik dan benar, khususnya dalam ranah formal. Terkadang untuk menuju ke arah tersebut, guru sudah mendapatkan benturan-benturan permasalahan, misalnya tidak adanya KBBI versi cetak di sekolah, bahkan kamus yang sederhana pun masih minim. Selain itu, ada beberapa kelemahan apabila menggunakan kamus cetak. Ada beberapa alasan mengapa kamus cetak masih kurang memuaskan para pemakainya. Menurut Keraf (2006:45), alasan pertama adalah keterlambatan waktu antara pengetikan dan penerbitan. Seorang penyu- 
sun kamus (leksikograf) mencatat kata-kata baru hanya sampai sebelum kamus itu diterbitkan. Waktu yang diperlukan selama pengetikan, pencetakan, sampai dengan penerbitan tidak sedikit. Semua itu dapat memakan waktu yang lama sehingga pada saat diterbitkan, kamus yang dibuat sudah ketinggalan zaman karena sudah muncul kata-kata baru yang belum sempat tercatat sebelum kamus dibuat. Oleh karena itu, salah satu upaya yang dapat dilakukan guru di sekolah dasar, yaitu dengan memanfaatkan KBBI V versi daring dalam pembelajaran bahasa Indonesia. Munculnya aplikasi KBBI $\mathrm{V}$ daring dengan berbagai fitur tersebut dapat membantu atau mempermudah guru dan sisw a dalam memecahkan masalah kebahasaan yang dihadapinya, khususnya yang berkaitan dengan lem a atau kata, baik penulisan maupun arti atau maknanya. Selain itu, dengan adanya KBBI $V$ dapat membantu guru atau pun sisw a untuk mencari kata dan melihat baku dan tidak baku.

Beberapa aplikasi kamus yang ditaw arkan di android, kita harus dapat memilih aplikasi kamus yang tepat, valid, dan lengkap, yaitu KBBI V daring yang dirilis oleh Badan Pengembangan Bahasa dan Perbukuan. KBBI V daring tersebut dapat diunduh dan dimanfaatkan dengan sebaik-baiknya oleh para pengguna. Diharapkan KBBI V versi daring ini dapat memberikan kontribusi positif terhadap kebahasaan bagi masyarakat. Berikut ini tampilan KBBI V versi daring. Pengguna dapat dengan mudah memanfaatkan kamus daring tersebut.

KBBI $V$ digunakan untuk mencari kata dan melihat baku dan tidak baku. Hal ini akan mempermudah dan membiasakan siswa untuk menggunakan KBBI $V$ versi daring apabila adakeraguan dalam menuliskan kata baku atau pun mencari makna atau arti sebuah kata. Oleh karena itu, penulis akan memaparkan tulisan yang berjudul "Pemanfaatan KBBI V Versi Daring dalam

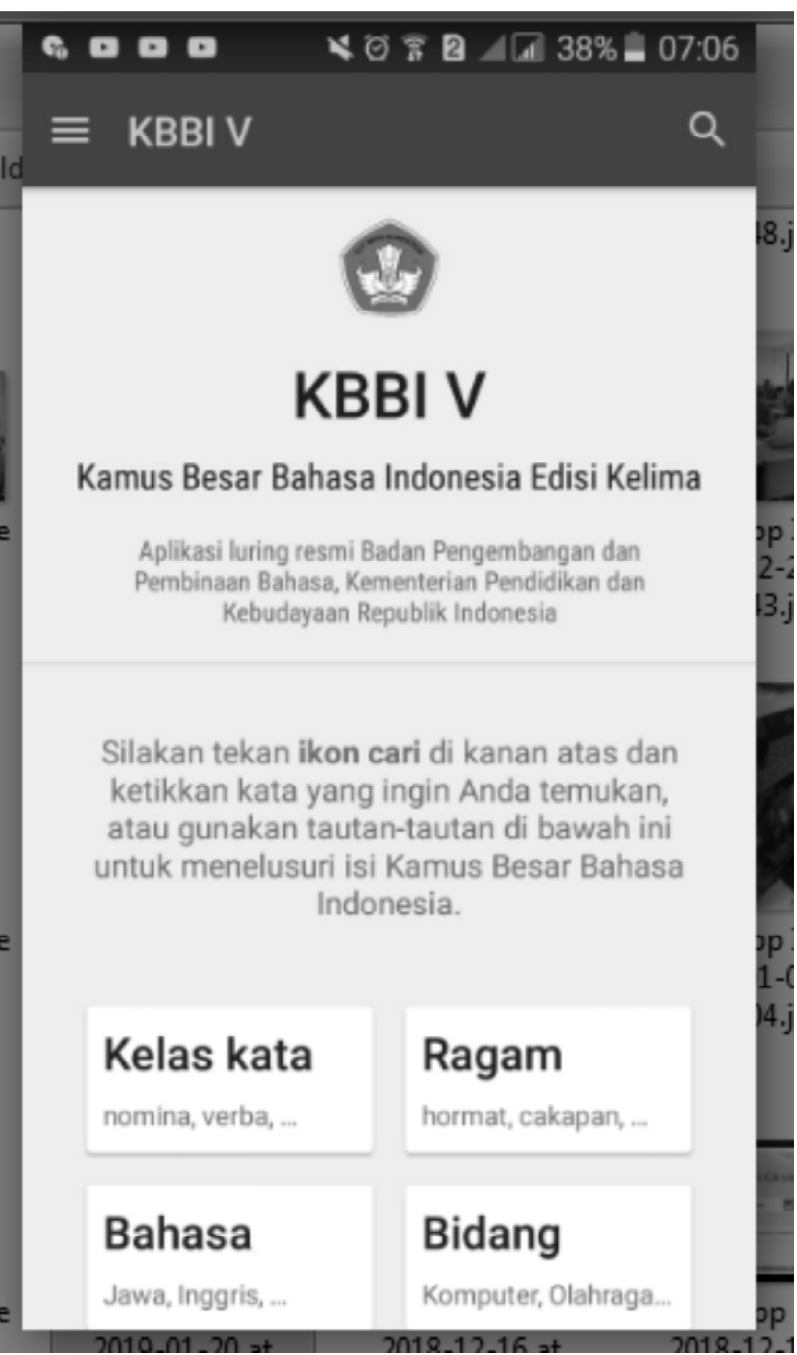

\section{Gambar 1. Tampilan Kamus KBBI edisi V}

Pengajaran Bahasa Indonesia di Sekolah Dasar".

Tujuan penulisan artikel ini, yaitu untuk mendeskripsikan pemanfaatan KBBI V versi daring dalam pengajaran bahasa Indonesia di sekolah dasar agar mempermudah guru dan siswa untuk mengetahui penulisan kata baku dan arti yang tepat sesuai dengan KBBI.

Metode yang dipakai dalam pembahasan ini adalah metode deskriptif kualitatif. Data berupa kata-kata yang telah sering digunakan anak anak, baik tulisan maupun lisan. Adapun teknik yang digunakan, yaitu dengan teknik baca dan catat. Sebelum menuliskan artikel ini, dilakukan pengamatan untuk mengumpulkan data serta memilih 
data yang berkaitan dengan masalah yang dibahas. Setelah data terkumpul, dilakukan penganalisisan berdasarkan urutan kata yang akan dikaji. Adapun langkah-langkah yang digunakan untuk menganalisis data, sebagai berikut.

a. Mengurutkan kata-kata yang sering diucapkan anak-anak kemudian dicocokkan dalam $K B B I$.

b. Mengklasifikasikan kata-kata berdasarkan ka-tegori- atau kriteria sesuai dengan ciri-ciri yang ditentukan.

Penganalisisan dan pendeskripsian terhadap kata yang telah diklasifikasikan berdasarkan kata baku yang benar dan mikrostruktur kata. Pendeskrip-sian tersebut mempertimbangkan benar atau salahnya bahasa yang digunakan, sesuai dengan tujuan pembahasan, yaitu penulisan serta pengucapan kata baku yang tercantum dalam KBBI.

Kata dengan penjelasan arti atau makna, kelas kata, serta contoh kalimat yang tertulis pada kamus akan membantu penggunanya, termasuk guru dan siswa sekolah dasar. Dengan memanfaatkan kamus, diharapkan siswa sejak sekolah dasar sudah mengetahui dan memahami bahasa Indonesia yang benar. Hal ini menjadi modal awal yang baik untuk mempelajari bahasa Indonesia pada jenjang berikutnya.

\section{PEMBAHASAN}

Secara historis, penggunaan bahasa Indonesia sebagai media pengajaran tidak dapat dilepaskan dari pemilihan bahasa ini sebagai bahasa nasional ketika dikumandangkan Sumpah Pemuda pada tahun 1928. Untuk pembentukan bangsa, pemilihan itu menguntungkan, meskipun mengesampingkan peran bahasa-bahasa daerah besar, seperti bahasa Jawa dan Sunda.
Bahasa Indonesia adalah salah satu mata pelajaran yang wajib dipelajari di setiap jenjang sekolah, tanpa terkecuali jenjang sekolah dasar. Pelajaran ini sering dianggap remeh dan membosankan. Pada umumnya, siswa lebih suka mata pelajaran matematika atau ilmu pengetahuan alam daripada bahasa Indonesia. Bahkan, siswa sekolah dasar pada umumnya akan lebih bangga bisa menghitung dengan cepat daripada bisa berbahasa Indonesia dengan baik dan benar.

Dalam mengembangkan kreativitasnya, siswa sekolah dasar harus berpikir kreatif untuk mengembangkan kemampuan dasar yang memang sudah dimilikinya. Kreativitas itu sendiri merupakan kombinasi baru dari elemen-elemen yang sudah ada, kemudian dicampur dan digabung seperti yang diinginkan. Jika dikaitkan dengan kegiatan pembelajaran berbahasa Indonesia sebagai sarana, kreativitas siswa itu sangat mungkin untuk berkembang. Seperti sekarang ini, keberadaan sarana Kamus Besar Bahasa Indonesia (KBBI) edisi $\mathrm{V}$ yang berbentuk dalam jaringan (daring) dapat memudahkan siswa dan guru untuk mengaksesnya. Oleh karena itu, perlu adanya pemanfaatan KBBI edisi $\mathrm{V}$ daring dalam pembelajaran bahasa di sekolah, termasuk sekolah dasar.

Perlu kita ketahui bahwa salah satu panduan utama bahasa Indonesia adalah berwujud kamus. Selama bertahun-tahun kamus bahasa Indonesia hanya tersedia dalam bentuk cetak saja. Ketika kamus Oxford atau pun kamus besar bahasa lainnya tersedia dalam bentuk digital dengan cepat, peminat atau pengguna bahasa Indonesia harus menunggu begitu lama untuk menikmati Kamus Besar Bahasa Indonesia (KBBI) edisi terbaru dalam versi daring yang mudah untuk diakses di era modern ini. Sebelum membahas KBBI edisi $\mathrm{V}$ versi daring akan dijelaskan secara singkat KBBI terlebih dahulu. 
KBBI edisi ketiga diterbitkan pada tahun 2005 dengan versi web yang dirilis pada tahun 2008. Sementara itu, KBBI edisi keempat yang versi cetaknya dirilis pada tahun 2008. Baru pada tahun 2016 KBBI hadir dalam wujud dalamjaringan. Delapan tahun bukanlah waktu yang singkat. Di era globalisasi yang semuanya berjalan dengan begitu cepat. Kita ketinggalan satu windu untuk mengejar teknologi kamus daring tersebut. Tampaknya harus menunggu waktu yang cukup lama dari pemerintah. Hal ini mungkin karena ketersediaan tenaga dan anggaran yang masih kurang dibandingkan dengan negara-negara maju.

Namun, kita masih beruntung karena memiliki lembaga yang menangani bahasa, yaitu Badan Pengembangan dan Pembinaan Bahasa yang saat ini berubah nama lagi menjadi Badan Pengembangan Bahasa dan Perbukuan. Setidaknya, ada yang mendorong pemerintah untuk memajukan bahasa Indonesia, salah satunya dengan inisiatif yang luar biasa untuk merilis KBBI dalam jaringan. Perkembangannya pun begitu cepat dan dapat dinikmati oleh penggunanya. Selang beberapa bulan setelah KBBI IV dirilis versi dalam jaringan, KBBI edisi kelima pun hadir juga dalam wujud dalam jaringan (daring). Bahkan, KBBI V hadir terlebih dahulu dalam bentuk digital daripada versi cetaknya. Hal ini perlu diapresiasi oleh masyarakat penggunanya, salah satunya guru dan siswa untuk memanfaatkan KBBI V daring ini dalam pembelajaran bahasa di sekolah.

Kemajuan yang luar biasa ini membuat guru dan siswa penasaran untuk menilik lebih lanjut KBBI V versi daring. Seberapa bisa diandalkannya situs yang punya peranan begitu penting bagi para guru dan siswa ini. Lalu bagaimana kualitasnya jika dibandingkan dengan situs-situs KBBI edisi-edisi sebelumnya.

KBBI V versi daring ini hadir dengan banyak perubahan dibanding versi-versi sebelumnya. Perubahan yang paling terasa jelas terdapat di konten yang jumlahnya mencapai 127.036 kosakata. Berbeda cukup signifikan dibanding KBBI IV yang disebut memiliki lebih dari 90.000 lema.

Selain itu, hal yang cukup mengejutkan penggunanya, yaitu beragamnya fitur-fitur baru di KBBI V versi web. Dalam sebuah kamus, hanya satu fitur yang wajib dimiliki, yaitu kemampuan untuk mencari arti dari sebuah kata. Jika kamus tersebut mampu menyelesaikan masalah tersebut, dapat dibilang kamus itu sudah hampir memenuhi fungsi utamanya.

Akan tetapi, situs KBBI V versi daring ini memiliki sebuah fitur yang sempat membuat beberapa pengguna bingung, yaitu fungsi untuk mendaftarkan akun. Namun, setelah dipahami untuk apa pengguna mendaftarkan akun, ternyata ada beberapa hal yang dapat dilakukan pengguna selain mencari arti di kamus daring. Menurut penjelasan di situsnya, berikut adalah fitur-fitur tambahan yang bisa didapatkan pengguna terdaftar, antara lain, sebagai berikut.

1. Pencarian entri berdasarkan huruf awal, popularitas entri, pencarian terakhir, kelas kata, ragam, bidang, dan bahasa.

2. Tautan kata turunan, kata gabungan, peribahasa, dan idiom dari kata yang dicari.

3. Pengusulan entri, makna, dan contoh baru dalam KBBI.

4. Pengusulan perbaikan entri, makna, dan contoh dalam KBBI.

5. Penambahan tautan makna pada hasil cari.

6. Bantuan pencarian entri dengan frasa ketika membuat usulan.

7. Akses melihat detail dan sejarah redaksi dari sebuah entri.

8. Akses penelusuran makna.

9. Tautan pencarian entri ke Google. 
Memang sebagian besar dari daftar fitur yang disampaikan di atas, banyak yang tidak dipahami dan tidak digunakan oleh penggunanya. Hal ini mungkin karena kekurangtahuan pengguna KBBI V daring tersebut.

Satu hal yang terasa berbeda dan langsung mudah dirasakan adalah fitur untuk memberikan saran kosakata. Sebagai pengguna terdaftar, Anda dapat menyarankan arti kata tambahan ke KBBI, atau jika kata yang Anda cari tidak dapat ditemukan, Anda pun bisa memberikan saran agar kata tersebut dimasukkan ke KBBI. Kata yang pengguna rekomendasikan tentunya tidak serta-merta langsung menjadi bagian diksi baru dari KBBI. Saran tersebut akan dikirimkan ke redaktur yang bertanggung jawab dan disaring apakah benar-benar layak untuk dimasukkan. Misalnya, saya sudah menyarankan kata "alien" agar dimasukkan juga ke KBBI V, mengingat ada beberapa kata turunan di KBBI yang menggunakan kata "alien," tetapi kata dasar "alien" sendiri tidak dapat ditemukan di daftar kosakata kamus ini.

Bagaimana proses penyaringan serta apakah kosakata yang disarankan tersebut akan masuk ke KBBI edisi cetak juga belum saya ketahui. Untuk sementara, kita harus menunggu sampai saran saya mendapatkan tanggapan, baru setelah itu artikel ini akan kami perbaharui tergantung respons yang diberikan.

Selain pengguna umum dan terdaftar, KBBI V juga memiliki klasifikasi pengguna lainnya, seperti editor, redaktur, validator, dan admin utama. Tentunya tidak sembarang pengguna akan bisa memperoleh akses ini.

Sebagai seorang guru, editor sekaligus penulis, diharapkan sering membuka situs KBBI V. Penggunaannya pun tidak lamalama. Biasanya saya langsung menekan tombol Ctrl+T, mengetikkan huruf $k$ yang langsung memunculkan rekomendasi situs KBBI yang paling sering saya buka, mengetikkan kata yang mau dicek, tekan tombol enter, kemudian menutup laman tersebut dan langsung melanjutkan pekerjaan.

Segala proses tersebut bisa berjalan dalam waktu kurang dari sepuluh detik, semuanya berkat desain web yang simpel dan fakta bahwa apa yang saya ketik akan langsung muncul di boks teks pencarian tanpa perlu menekan tombol apa pun atau menggerakkan tetikus saya.

Sayangnya hal tersebut tidak dapat dilakukan di KBBI V versi web karena begitu dibuka situs ini tidak langsung menaruh fokus kursor di boks pencarian seperti aplikasi web yang berfokus pada pencarian lain pada umumnya. Hal ini sempat terjadi juga di KBBI IV, tetapi langsung diperbaiki beberapa hari setelah saya mengaksesnya. Semoga saja perbaikan yang sama juga akan dilakukan untuk KBBI V.

Selain fitur minor di atas, satu hal yang ada di KBBI IV, tetapi tidak ada di KBBI V adalah tautan langsung untuk menuju ke entri sebelum dan sesudah yang kita cari. Lagi-lagi memang hal yang terkesan sangat remeh, tetapi dampaknya cukup signifikan bagi pengguna yang cukup rutin dan butuh kecepatan seperti saya.

Keluhan lainnya bagi saya muncul dalam wujud kurang jelasnya tanda untuk fitur-fitur penting yang dimiliki KBBI V. Misalnya ikon untuk menyarankan makna atau kosakata baru. Situs ini menampilkan tautan tersebut dalam bentuk teks dan ikon tidak berwarna yang baru terlihat jelas ketika pengguna mengarahkan kursor ke atasnya. Hal ini sempat membuat saya bingung beberapa lama saat ingin memasukkan rekomendasi kata baru.

Terakhir, dan juga mungkin yang terkesan paling remeh dibanding lainnya muncul dari bagaimana cara situs KBBI V menampilkan pencarian. Di situs KBBI IV dan KBBI.web.id, pencarian bekerja dengan cara membawa pengguna ke tautan yang 
mengarah ke definisi kata yang dimaksud. Dengan begitu, membagikan tautan ke orang lain atau ke media sosial pun jadi jauh lebih mudah. Sebenarnya kamu bisa saja melakukan ini di KBBI V, tetapi hal tersebut harus dilakukan dengan cara mengetikkan kosakata secara manual di boks tautan penjelajah web kamu.

Secara langsung, kekurangan yang saya rasakan ketika mengakses situs KBBI terbatas sampai di situ saja. Tapi tetap ada beberapa peningkatan yang saya rasa bisa dilakukan. Misalnya, peningkatan kualitas SEO. Karena saat ini saja, mengetikkan "KBBI V" di Google tidak akan langsung mengarahkan orang ke situs terbaru KBBI, tetapi malah mengarah ke situs KBBI IV dan beberapa media yang mengabarkan peluncuran KBBI $\mathrm{V}$ saja.

Setakat ini, ketika kita ingin mencari definisi kata-kata dalam bahasa Indonesia, acuan yang baik adalah Kamus Besar Bahasa Indonesia (KBBI). Hal ini disebabkan oleh alasan bahwa KBBI merupakan kamus bahasa Indonesia yang berterima. Menurut (Sulastri, 2016:203), dalam penelitian “Keberterimaan dan Keterpakaian Kamus Besar Bahasa Indonesia bagi Pengajar" dari 56 responden yang dijadikan objek pengumpulan data, seluruhnya (100\%) menyatakan bahwa pengajar memerlukan KBBI. Namun, keterpakaiannya hanya $59 \%$.

Banyak cara memaksimalkan untuk pengajaran Bahasa dan Sastra di Sekolah Dasar, di antaranya, yang akan di bahas dalam artikel ini. Dengan demikian, dimungkinkan bahasa Indonesia dapat diterima pada siswa sepanjang zaman. Salah satu bentuk memaksimalkan dalam pengajaran Bahasa Indonesia dan sastra yang berkaitan dengan kebahasaan dengan adanya membuka kamus sebagai pedoman untuk kebenaran kata baku.

\section{PENUTUP}

Pembelajaran bahasa di sekolah dasar sering menjadi kendala karena banyak kata tidak baku yang digunakan siswa. Hal ini terjadi karena dari kebiasaan awal atau pun memang sama sekali belum mengetahui penulisan yang benar. Kita memahami bahwa berbahasa Indonesia dengan baik dan benar merupakan salah satu bentuk untuk mempertahankan bahasa Indonesia. Oleh karena itu, perlu pembinaan penggunaan bahasa yang baik dan benar kepada siswa sekolah dasar melalui pemanfaatan KBBI V versi daring dalam pengajaran bahasa Indonesia. Kebiasaan membuka atau memanfaatkan KBBI V versi daring ini merupakan hal yang harus dijalankan. Hal tersebut juga dimaksudkan untuk membiasakan siswa sekolah dasar dalam penggunaan bahasa Indonesia ini dapat dipraktikkan dengan benar, baik dalam penggunaan bahasa lisan maupun tulisan. Selanjutnya, pembelajaran bahasa Indonesia dengan kebiasaan membuka KBBI V daring akan lebih memaksimalkan pemahaman dan penggunaan kata-kata baku sehingga kesalahan-kesalahan dapat diminimalisasikan.

Hadirnya KBBI edisi V di web sebelum muncul versi cetaknya jelas merupakan angin segar tersendiri. Peningkatan yang disajikan dibandingkan situs-situs KBBI sebelumnya pun, baik yang resmi maupun tidak resmi, sangatlah terasa. Namun, saat ini situs KBBI V masih memiliki sejumlah kekurangan minor yang berpotensi merusak pengalaman pengguna. Beberapa keluhankeluhan di atas bisa dikatakan merupakan sesuatu yang cukup mudah diperbaiki, dan akan sangat luar biasa jika perbaikan itu dapat dilakukan oleh tim pengembang situs ini. Akan tetapi, yang jelas keberadaan KBBI edisi $\mathrm{V}$ adalah sesuatu yang sangat perlu kita apresiasi. Setidaknya kita semua tidak perlu membeli kamus seharga ratusan ribu rupiah 
dengan tebal ribuan halaman lagi hanya untuk mengecek ata-kata yang biasa kita gunakan sehari-hari.

\section{DAFTAR PUSTAKA}

Alwi, Hasan. 2003. Tata Bahasa Baku Bahasa Indonesia (Edisi Ketiga). Jakarta: Balai Pustaka.

Damayanti, Wahyu. 2016. "Bentuk Derivasi Bahasa Melayu Dialek Sambas" dalam Kandai Jurnal Bahasa dan Sastra Volume 12 Nomor 2 November 2016 hlm. 255-268.

Eggins, S. (2004). An introduction to functional linguistics. London: Continuum Internasional Publishing Group.

Keraf, Gorys. 2006. Diksi dan Gaya Bahasa. Flores: Nua Indah.

Kridalaksana, Harmurti. 2011. Kamus Linguistik (Edisi Keempat). Jakarta: PT Gramedia Purtaka Utama.

Kurniasih, Ika. 2014. “Analisis Kata Kamus Bahasa Indonesia untuk Pelajar" Skrip- si. Yogyakarta: Universitas Negeri Yogyakarta.

Kulsum, Umi. 2015. "Sufiks -is dan -ik serta Probkatatikanya dalam Bahasa Indonesia" dalam Jurnal Metalingua Volume 13 Nomor 2 Desember 2015 hlm 241260.

Metalingua, Vol. 16 No. 1, Juni 2018:117132

Pusat Bahasa. 2008. Kamus Besar Bahasa Indonesia Pusat Bahasa (Edisi Keempat). Jakarta: PT Gramedia Pustaka Utama.

Sugono, Dendy et al. 2008. Kamus Besar Bahasa Indonesia (Edisi Keempat). Jakarta: PT Gramedia Pustaka Utama.

Sulastri, Hari. 2016. “Keberterimaan dan Keterpakaian Kamus Besar Bahasa Indonesia bagi Pengajar" dalam Prosiding Seminar Hasil Penelian Kebahasaan dan Kesastraan. Yogyakarta: Balai Bahasa Daerah Istimewa Yogyakarta. 